\title{
A Study on the Characteristics of Chord Generation of Yeongjin Port Breakwater
}

\author{
Bong-Young Kim¹, Zhixing Tian² and Myung-Jin Bae ${ }^{3 *}$ \\ ${ }^{1}$ Soong-sil University, Department of Information and telecommunication Engineering, Seoul, 06978, Korea. \\ Orcid Id : 0000-0002-3553-039X \\ ${ }^{2}$ Soong-sil University, Department of Information and telecommunication Engineering, Seoul, 06978, Korea. \\ Orcid Id : 0000-0003-3882-2459 \\ ${ }^{3}$ Soong-sil University, Department of Information and telecommunication Engineering, Seoul, 06978, Korea \\ Orcid Id : 0000-0002-7585-0400
}

\begin{abstract}
:
Around us, objects or structures that inadvertently generate sounds can sometimes be seen. Although Korea's Youngjin port breakwater is a huge artificial structure, it makes a chord on a scale to make a sound. In this study, we tried to characterize the sound of Youngjin port breakwater by applying a signal processing technique. As a result of analysis, the Youngjin port breakwater generates $\mathrm{C}(\mathrm{Do}), \mathrm{E}(\mathrm{Mi})$, and $\mathrm{G}(\mathrm{So})$ sounds regardless of the change in time, and 3 sounds are generated in a certain order. Also, $\mathrm{G}(\mathrm{So})$ may not appear depending on the strength of the wind and waves. Once the $\mathrm{G}(\mathrm{So})$ sound is generated, the $\mathrm{C}(\mathrm{Do})$ sound becomes shorter and the $\mathrm{E}(\mathrm{Mi})$ sound becomes longer. Depending on the situation, the three sounds appearing in different forms are mixed to have a chordlike tone. Through these analysis results, it was confirmed that the Youngjin port breakwater is a sound system in which sound is sequentially resonated due to natural or artificially formed
\end{abstract}

Keyword: Youngjin Port, Breakwater, Chord, Resonance, Sound System

\section{INTRODUCTION}

There are terrains and objects around our lives that make unintentional sounds. Such sounds give people wonders of nature, and sometimes local specialties. In South Korea, the Youngjin port breakwater that touches the East Sea makes a sound similar to a pipe organ forming a chord when a wave strikes. Even though breakwater is a huge artificial structure built by humans, it is difficult to find a case in which a sound is produced with a clear scale as in the Youngjin port. By clarifying the generation principle of chords generated in Youngjin port breakwater, it is possible to raise interest in the land [1-4]. spaces.

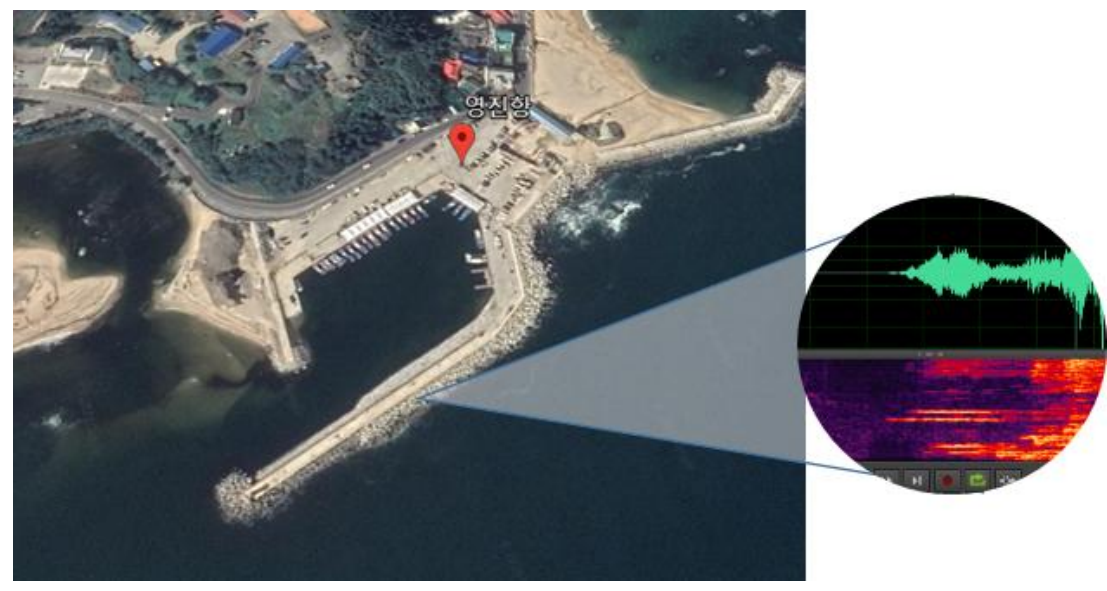

Fig 1. Youngjin port breakwater sound generation [4]

Breakwater is a huge structure that is built to protect the port by blocking waves from the open ocean. Artificial breakwater is installed because natural breakwater cannot protect a port's buildings or ships. The principle of breakwater blocking the wave is a method of dispersing the energy of the wave by breaking and accepting the wave through small gaps. Breakwater sometimes creates a passageway connecting the inland sea and the open ocean, while preventing heavy waves to prevent pollution of seawater. In addition, the damaged space may be generated due to the impact of seawater, which is a ton 
unit fluid. For this reason, various spaces exist inside breakwater. Youngjin port breakwater generates sound due to vibration of various spaces due to the inflow of waves inside. At this time, among various sound components, sounds of a scale similar to $\mathrm{C}(\mathrm{Do}), \mathrm{E}(\mathrm{Mi})$, and $\mathrm{G}(\mathrm{So})$ are mainly heard [5$6]$.

In this study, the phenomenon that the wave meets the artificial structure called breakwater and forms a chord was analyzed through a signal processing technique. Chapter 2 describes the principle of resonance in which a specific sound is generated in an empty space, and Chapter 3 describes the scale of sound through a musical instrument. Chapter 4 compares and analyzes the sound of Youngjin port breakwater and chord of musical instrument through experiments and results, and concludes in Chapter 5.

\section{SOUND GENERATION IN SPACE}

\subsection{White noise}

White noise refers to noise in which the sound components are constant over all frequency bands. White noise mixes all sounds to form a random waveform whose frequency, amplitude and phase are constantly changing. White noise exists around us in natural phenomena such as wind sound, waves sound and waterfall sound. Since this white noise contains energy in the broadband, it can generate sound by exciting various sound systems. Figure 2 shows the sound components of construction noise, wind sound, and white noise. Figure 2 shows that the wind sound is similar to white noise because it has sound components in a wide band [6-8].

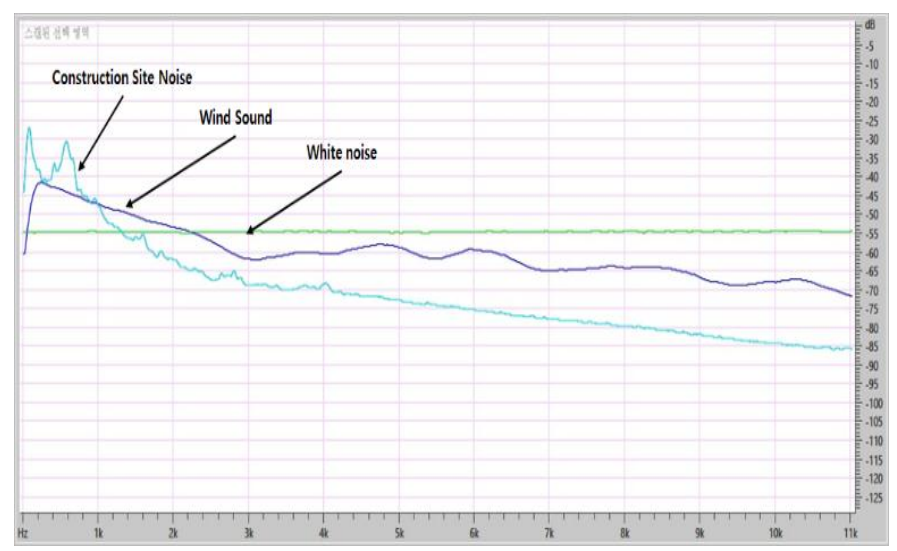

Fig 2. Comparison of sound components between wind sound, white noise and construction noise

\subsection{Helmholtz resonator}

Resonator is a device that naturally vibrates at a certain frequency with a larger amplitude than other frequencies. The resonator is used to generate a specific frequency, or to select a specific frequency from a signal. The musical instrument can be said to be a resonator that generates sound waves of a specific frequency. In the case of a wind instrument, sound is generated by either open air column resonance on both sides of the tube or closed air column resonance on one side. Through the Helmholtz resonator, it is possible to check the resonant frequency of air in an irregularly shaped internal structure. The artificial and natural space created inside the breakwater is an irregular space that does not consider the production of sound. The sound of irregular spaces such as breakwater can be explained by the Helmholtz resonator. Figure 3 shows the Helmholtz resonator with volume "V", inlet area "S", and inlet length "L". The relationship between the irregular space and resonance frequency is shown in Eq. (1) [6-7].

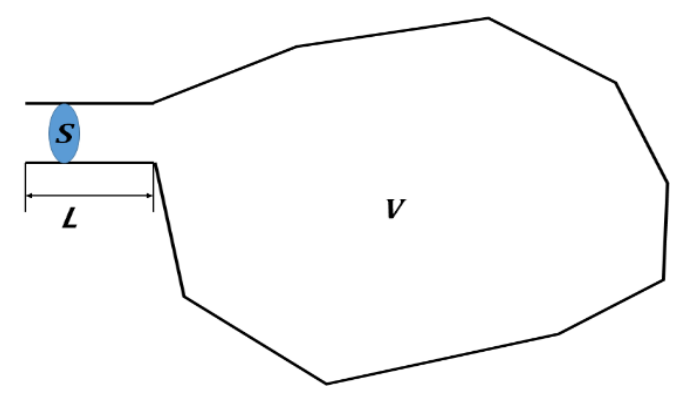

Fig 3. Helmholtz resonator [6]

$$
\begin{aligned}
f & =\frac{C}{2 \pi} \sqrt{\frac{S}{V L_{e q}}} \\
L_{e q} & =L+0.3 D
\end{aligned}
$$

$L_{e q}$ is the equivalent length of the neck with end correction. $\mathrm{D}$ is the hydraulic diameter of the neck.

$\mathrm{L}$ is the actual length of the neck.

In Figure 3 and Eq. (1), it can be seen that the resonance frequency of the internal air is determined by the volume, the area of the inlet, and the length of the inlet in an irregular space. That is, in the case of a structure such as a Helmholtz resonator, when an impulse having various frequency components is input, the air inside the space resonates at a specific frequency. Looking at Eq. (1), it can be seen that when the space inside the resonator is wide or the length of the entrance is long, it resonates with a low-pitch tone, and when the area of the resonator entrance is wide, it resonates with a high-pitch tone [6-7].

\section{SCALE OF MUSICAL INSTRUMENT}

\subsection{Octave}

Human auditory sense is very sensitive to changes in low frequencies, while relatively insensitive to changes in high frequencies. One of the ways to classify bands by reflecting the auditory sense characteristics of these people's frequencies is octave. An octave is a tune between two tones whose frequencies are doubled. For example, for an interval between $100 \mathrm{~Hz}$ and $200 \mathrm{~Hz}$, the next highest tone is $400 \mathrm{~Hz}$. That is, when the tune increases at the same interval, the difference $(N)$ 
International Journal of Engineering Research and Technology. ISSN 0974-3154, Volume 13, Number 6 (2020), pp. 1379-1385

(C) International Research Publication House. https://dx.doi.org/10.37624/IJERT/13.6.2020.1379-1385

between the frequency $\left(f_{1}, f_{2}\right)$ and tune is expressed as Eq. (2) [6-9].

$$
N=\log _{2}\left(\frac{f_{2}}{f_{1}}\right)
$$

That is, in case of $f_{2}=8 f_{1}$, the frequency is 8 times different, but in $f_{2}=2^{N} f_{1}=2^{3} f_{1}$, the tune is 3 times different.

\subsection{Scale}

A musical instrument usually produces a sound on a scale that divides an octave into 12 levels. Table 1 shows the frequency of the musical instrument. Within a octave, the relationship between the frequency $\left(f_{0}\right)$ of the $\mathrm{C}(\mathrm{Do})$ scale and each scale $\left(f_{N}\right)$ can be expressed as Eq.(3) [6-9].

$$
f_{n}=f_{0} \sqrt[12]{2^{n}}, \quad n=0,1,2, \ldots, 11
$$

If the musical instrument expresses $\mathrm{C}(\mathrm{Do}), \mathrm{E}(\mathrm{Mi})$, or $\mathrm{G}(\mathrm{So})$, the frequencies corresponding to each scale are output together. Looking at Table 1, when expressing C(Do), E(Mi), and G(So) chord of 5 octave, sound with frequency components of $523 \mathrm{~Hz}$, $659 \mathrm{~Hz}$, and $784 \mathrm{~Hz}$ is produced.

\begin{tabular}{|c|c|c|c|c|c|c|c|c|}
\hline Scale & 1 & 2 & 3 & 4 & 5 & 6 & 7 & 8 \\
\hline C(Do) & 32.7032 & 65.4064 & 130.8128 & 261.6256 & 523.2511 & 1046.5020 & 2093.0050 & 4186.0090 \\
\hline $\mathrm{C \#}$ & 34.6478 & 69.2957 & 138.5913 & 277.1826 & 554.3653 & 1108.7310 & 2217.4610 & 4434.9220 \\
\hline $\mathbf{D}(\mathbf{R e})$ & 36.7081 & 73.4162 & 146.8324 & 293.6648 & 587.3295 & 1174.6590 & 2349.3180 & 4698.6360 \\
\hline D\# & 38.8909 & 77.7817 & 155.5635 & 311.1270 & 622.2540 & 1244.5080 & 2489.0160 & 4978.0320 \\
\hline $\mathbf{E}(\mathbf{M i})$ & 41.2034 & 82.4069 & 164.8138 & 329.6276 & 659.2551 & 1318.5100 & 2637.0200 & 5274.0410 \\
\hline $\mathbf{F}(\mathbf{F a})$ & 43.6536 & 87.3071 & 174.6141 & 349.2282 & 698.4565 & 1396.9130 & 2793.8260 & 5587.6520 \\
\hline F\# & 46.2493 & 92.4986 & 184.9972 & 369.9944 & 739.9888 & 1479.9780 & 2959.9550 & 5919.9110 \\
\hline G(So) & 48.9994 & 97.9989 & 195.9977 & 391.9954 & 783.9909 & 1567.9820 & 3135.9630 & 6271.9270 \\
\hline G\# & 51.9130 & 103.8262 & 207.6523 & 415.3047 & 830.6094 & 1661.2190 & 3322.4380 & 6644.8750 \\
\hline $\mathbf{A}(\mathbf{L a})$ & 55.0000 & 110.0000 & 220.0000 & 440.0000 & 880.0000 & 1760.0000 & 3520.0000 & 7040.0000 \\
\hline A\# & 58.2705 & 226.5409 & 233.0819 & 466.1638 & 932.3275 & 1864.6550 & 3729.3100 & 7458.6200 \\
\hline $\mathbf{B}(\mathbf{S i})$ & 61.7354 & 123.4708 & 246.9417 & 493.8833 & 987.7666 & 1975.5330 & 3951.0660 & 7902.1330 \\
\hline
\end{tabular}

Table 1. Standard frequency by scale

\section{EXPERIMENT AND RESULT}

Youngjin port breakwater sounds like a wind instrument when a wave strikes. The peculiarity is that the sound is generated by chording on three scales. In particular, when the northeast wind is blowing strongly, the wave that is driven into the breakwater becomes stronger and the sound becomes louder. The sound of Youngjin port breakwater was compared and analyzed with the sound components of the musical instrument. The sound sources used in the analysis were directly recorded and used. For each sound source, the resonance frequency and duration of sound were compared and analyzed through the sound wave spectrum. In addition, for the Youngjin port sound source, it was confirmed that the characteristics of the Youngjin port breakwater sound were maintained when the sound components corresponding to each scale were removed. Each sound source was quantized 32 bits after sampling $11025 \mathrm{~Hz}$. Audition CC was used as the used software. 


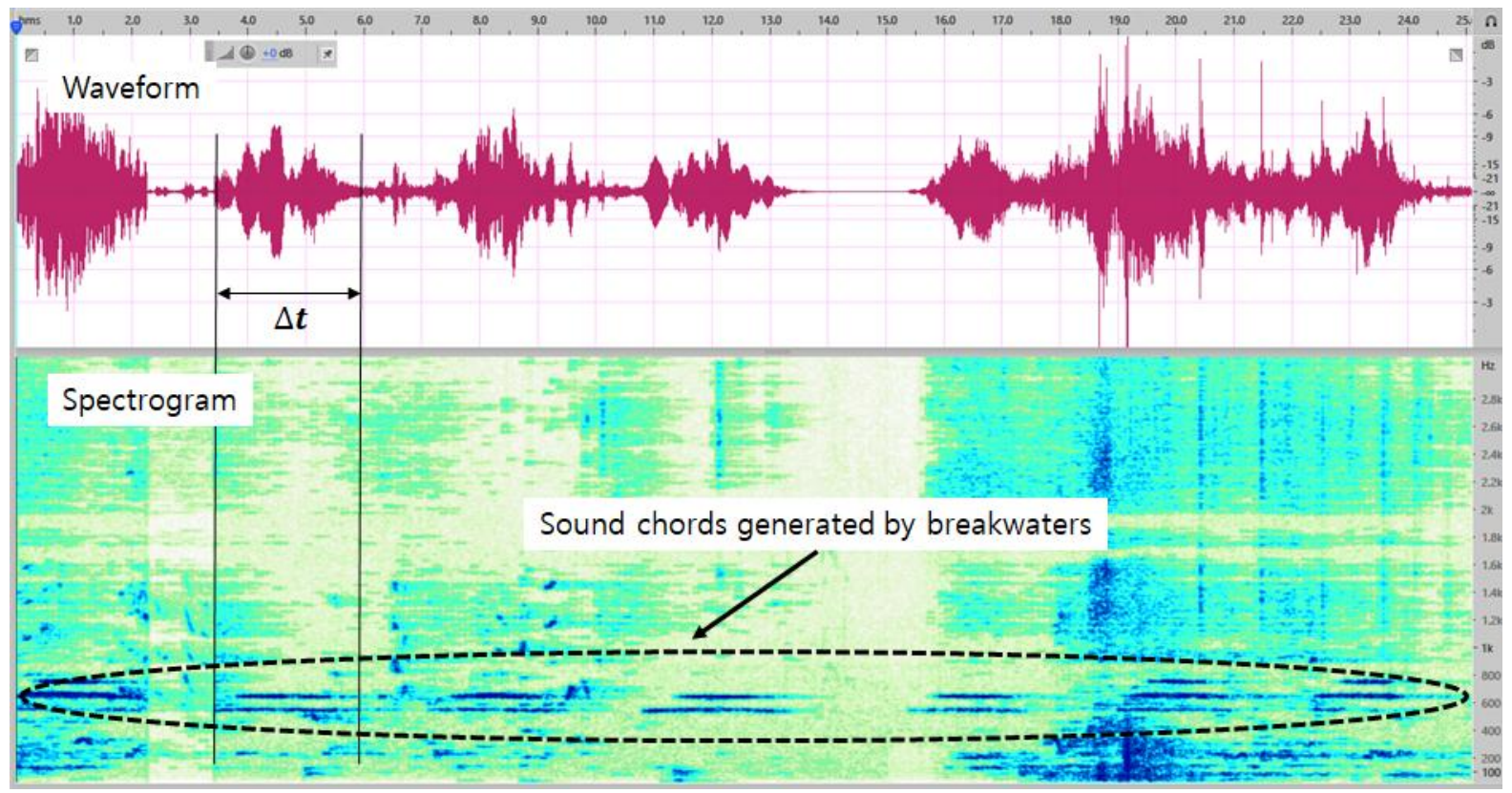

Fig 4. Waveform and Spectrogram of Youngjin port breakwater sound

Figure 4 shows the waveform and spectrogram of the sound coming from Youngjin port breakwater. In Fig. 4, the sound of chords is strongly heard during the time $(\Delta t)$ of sound waves with sound components in all bands. Also, in the case of chord coming from breakwater, the frequency component is constant regardless of the change in time. The chord is composed of two or three sounds. When the waves sound is small, two sounds appear, and when the waves sound is large, three sounds appear.

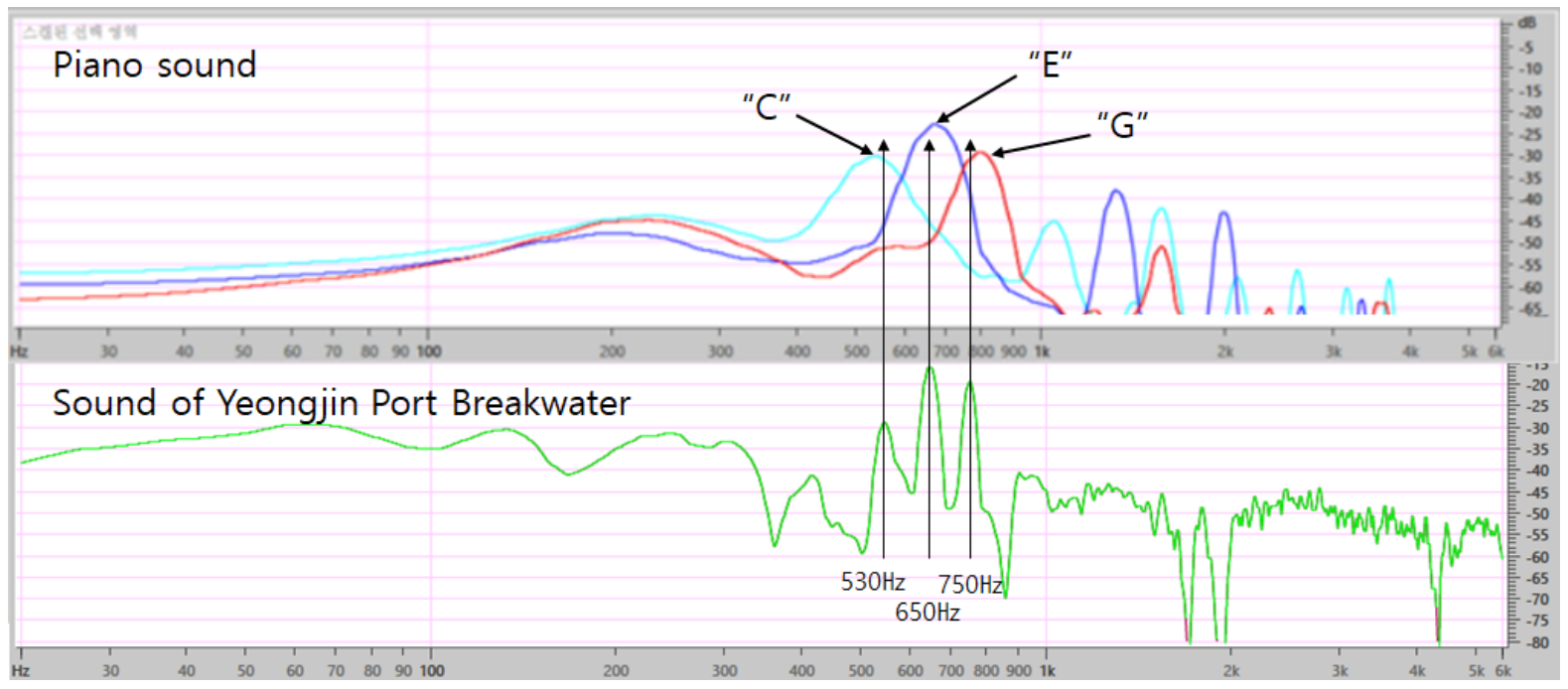

Fig 5. Frequency spectrum of piano sound and Youngjin port breakwater sound

Figure 5 shows the frequency spectrum of the piano's $C$ (Do), $\mathrm{E}(\mathrm{Mi})$, and $\mathrm{G}$ (So) sounds and the Youngjin port breakwater sound. In Figure 5, when hitting the $\mathrm{C}(\mathrm{Do})$ of the piano, the resonance occurs at about $520 \mathrm{~Hz}$, and the harmonics are generated at an integer multiple. Also, when hitting $\mathrm{E}(\mathrm{Mi})$ or $\mathrm{G}(\mathrm{So})$, it sounds at about $660 \mathrm{~Hz}$ and $780 \mathrm{~Hz}$. In the case of
Youngjin port breakwater sound, it can be seen that the sound mainly occurs at about $530 \mathrm{~Hz}, 650 \mathrm{~Hz}$, and $750 \mathrm{~Hz}$. Table 2 shows the results of measuring the resonance frequency and duration of the chords in the 7 times Youngjin port breakwater sound described in Figure 4. 
International Journal of Engineering Research and Technology. ISSN 0974-3154, Volume 13, Number 6 (2020), pp. 1379-1385

(C) International Research Publication House. https://dx.doi.org/10.37624/IJERT/13.6.2020.1379-1385

Table 2. The resonance frequency and duration of Youngjin port breakwater sound

\begin{tabular}{l|l|c|c|c|c|c|c|c}
\hline \multicolumn{2}{c}{ Sound source } & 1'st & 2'nd & 3'rd & 4'th & 5'th & 6'th & 7'th \\
\hline \hline \multirow{2}{*}{$\begin{array}{l}\text { 1'st } \\
\text { resonance }\end{array}$} & Frequency(Hz) & 530 & 530 & 530 & 530 & 530 & 530 & 530 \\
\cline { 2 - 9 } & Duration(sec) & 2.2 & 2.6 & 3.2 & 3.1 & 2.3 & 2 & 2 \\
\hline $\begin{array}{l}\text { 2'nd } \\
\text { resonance }\end{array}$ & Frequency(Hz) & 650 & 650 & 650 & 650 & 650 & 650 & 650 \\
\cline { 2 - 9 } & Duration(sec) & 2.4 & 2.16 & 3 & 2.9 & 2.1 & 2.2 & 2.2 \\
\hline $\begin{array}{l}\text { 3'rd } \\
\text { resonance }\end{array}$ & Frequency(Hz) & 750 & - & - & - & - & 750 & 750 \\
\cline { 2 - 9 } & Duration(sec) & 1.8 & - & - & - & - & 1.5 & 1.5 \\
\hline
\end{tabular}

Figure 6 is the sound waveform and frequency spectrum of attenuated sound components of $520 \sim 560 \mathrm{~Hz}, 620 \sim 660 \mathrm{~Hz}$, $730 \sim 760 \mathrm{~Hz}$ band about $30 \mathrm{~dB}$ for the Youngjin port breakwater sound in Figure 4. In the sound of Figure 6, where the relevant band is attenuated, only the waves sound or ambient noise remains, and the musical instrument sound is not heard.
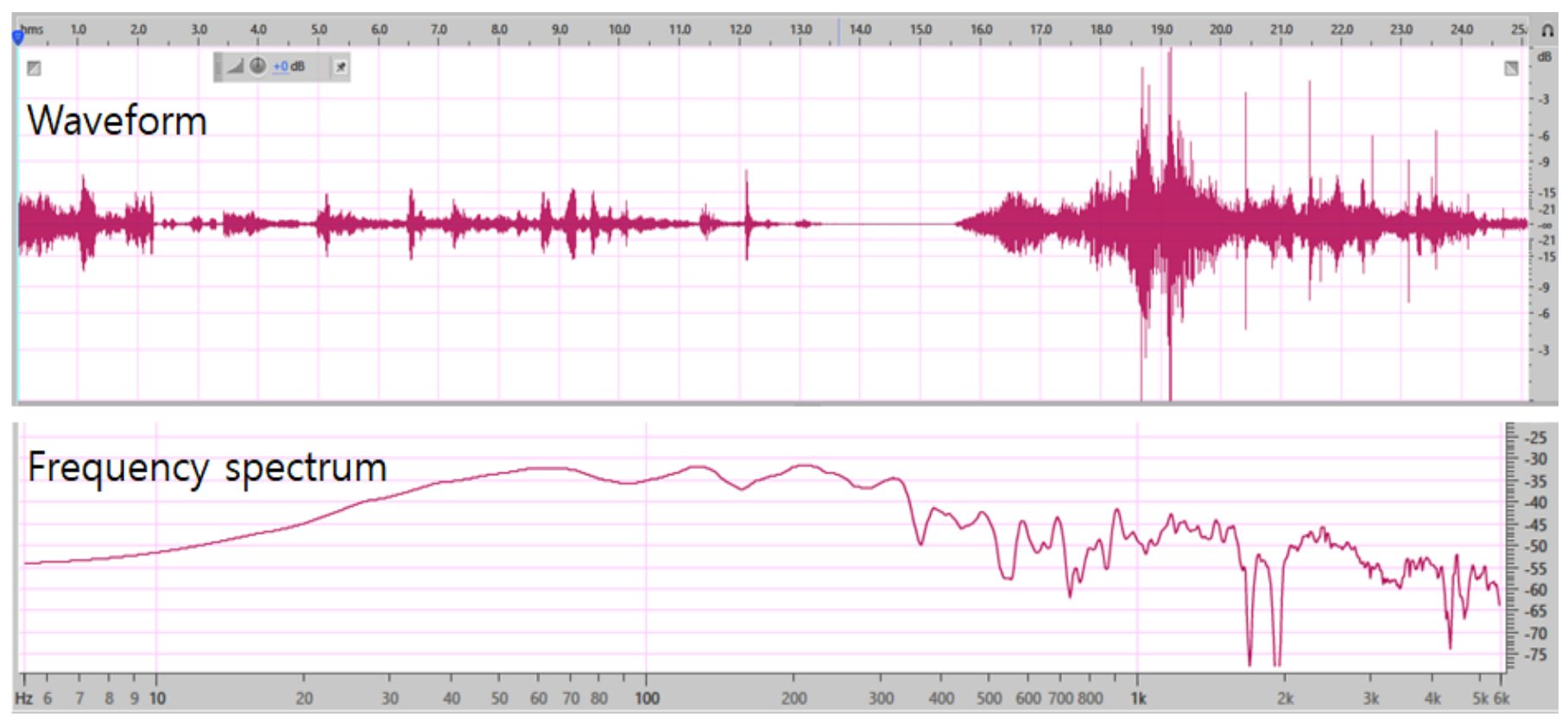

Fig 6. Youngjin port breakwater sound waveform and frequency spectrum with attenuated C(Do), E(Mi), and G(So) bands

In view of these results, Youngjin port breakwater can be viewed as a sound generator with three resonators placed in sequence. In addition, it can be seen that the sound of $\mathrm{C}(\mathrm{Do})$, $\mathrm{E}(\mathrm{Mi})$, and $\mathrm{G}($ So) makes a chord by making a sound in order by a strong wave or wind caused by the wave. Also, when the wave is weak, the energy is weak and the third resonator is not excited, so only $\mathrm{C}(\mathrm{Do})$ and $\mathrm{E}(\mathrm{Mi})$ sounds can be heard. On the other hand, when the $\mathrm{G}(\mathrm{So})$ sound is generated, it can be seen that the duration of $\mathrm{C}(\mathrm{Do})$ becomes shorter and the duration of $\mathrm{E}(\mathrm{Mi})$ becomes longer. The Youngjin port breakwater that generates sound can be expressed by the resonator structure as shown in Figure 7. 


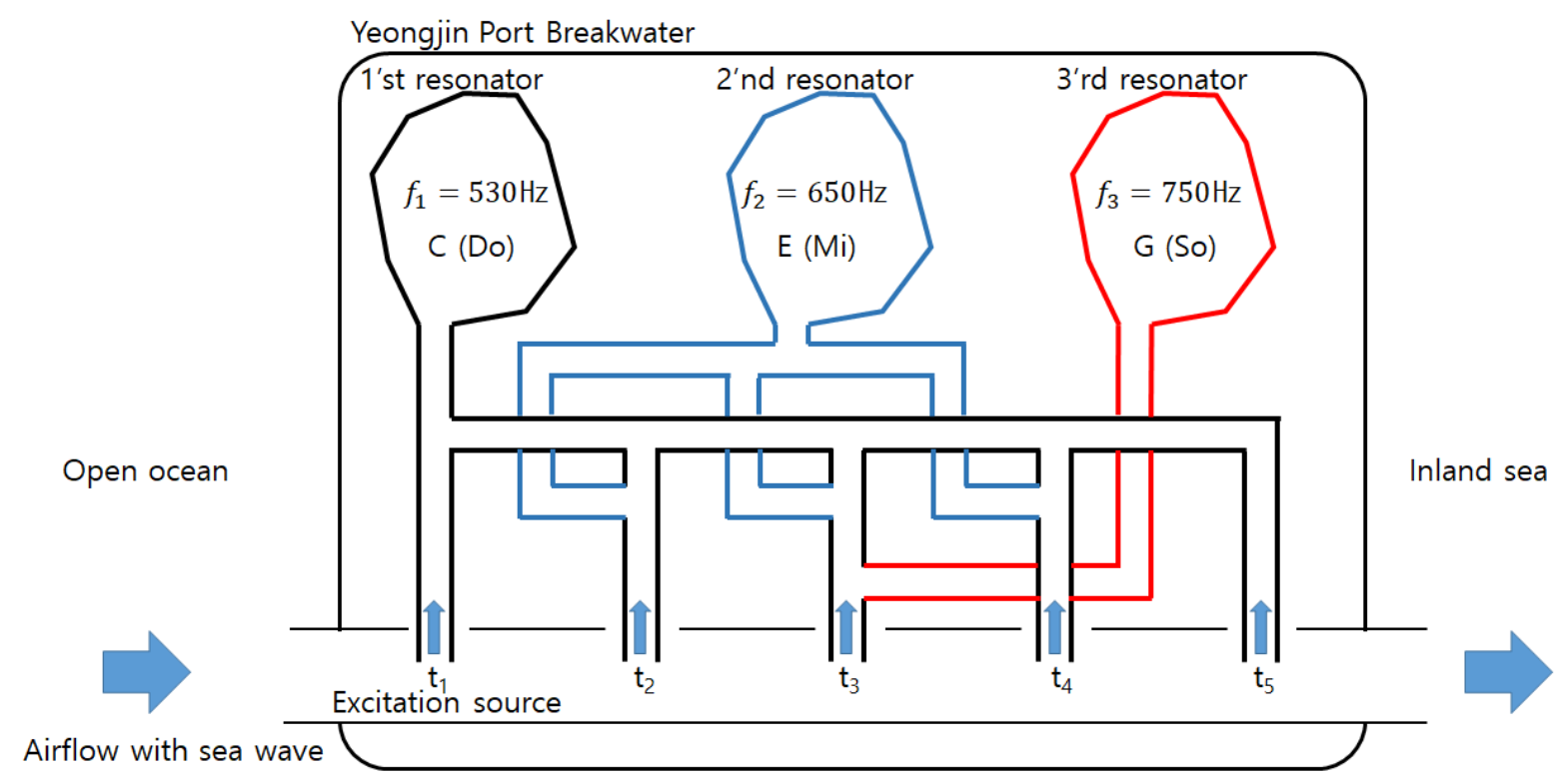

Fig 7. Resonator structure of Youngjin port breakwater

\section{CONCLUSION}

The strange sounds that occur around us give us wonders about nature, and sometimes fears. Research that grasps and clarifies the principle of sounds that occur around us can increase our interest in our homeland. Youngjin port breakwater produces sound with an accurate scale like a musical instrument even though it is a huge human-made structure. The sound of Youngjin port breakwater provides a novelty for tourists and acts as noise for residents.

In this study, the purpose of this study was to investigate the shape of sound and generation principle of sound by applying a signal processing technique to the breakwater sound of Youngjin port. As a result of the experiment in Chapter 4, it was confirmed that the sound in the Youngjin port breakwater generates $\mathrm{C}(\mathrm{Do}), \mathrm{E}(\mathrm{Mi})$, and $\mathrm{G}(\mathrm{So})$ sounds by wave and wind. In addition, there was an order of sound generation, and it was confirmed that the sound produced was different and the duration of the sound was different depending on the wave or wind intensity.

As a result, it can be seen that the Youngjin port breakwater is composed of a sound system in which resonators that produce $\mathrm{C}$ (Do), E (Mi), and G (So) sounds are sequentially connected. Due to this sound system structure, when the wave or wind is weak, $\mathrm{C}(\mathrm{Do})$ and $\mathrm{E}(\mathrm{Mi})$ sounds are generated, and the $\mathrm{C}(\mathrm{Do})$ sound continues for a long time. On the other hand, when the wave or wind is strong, the $\mathrm{C}(\mathrm{Do}), \mathrm{E}(\mathrm{Mi})$, and $\mathrm{G}(\mathrm{So})$ sounds appear, and the $\mathrm{C}(\mathrm{Do})$ sound becomes shorter and the $\mathrm{E}(\mathrm{Mi})$ sound becomes longer. The $\mathrm{C}(\mathrm{Do}), \mathrm{E}(\mathrm{Mi})$, and $\mathrm{G}(\mathrm{So})$ notes caused by the resonance phenomenon are mixed as chords to form the tone of Youngjin port breakwater only. Then, sound is propagated into the space such as a drain hole separately installed in the breakwater, and is heard in our ears.

It was confirmed that Youngjin port breakwater is generating sound due to natural or artificially formed space. The purpose of this study is to suggest that it is possible to analyze homeland in various ways through sound analysis.

\section{REFERENCE}

[1] Kim, B.-Y., Bae, M.-J., A study on the sound characteristics analysis of drum-sound rock, Journal of Engineering and Applied Sciences, 2018, 13(12), pp. $4414-4418$

[2] Bong-Young Kim, and Myung-Jin Bae, "A study on the sound investigation of wooden gong rock," The Journal of the Acoustical Society of America, Vol. 142, No. 1, pp. 2606, October 2017.

[3] Kim, B.-Y., Yi, E.-Y., Bae, M.-J., A study on the distinguish of the defective product of ceramic toilet by sound characteristics, Journal of Engineering and Applied Sciences, 2019, 14(4), pp. 1247-1252

[4] [googlemaps] Yeongjin Port

[5] https://m.blog.naver.com/PostList.nhn?blogId=ulsanport

[6] S. H. Kang. Fundamentals of Sound Engineering, SoundMedia, Korea (2007).

[7] S. T. Lee. Principles and Application of Sound, Cheong Moon Gak, Korea (2004).

[8] Myung-Jin Bae, and Sang-Hyo Lee, Digital Speech Analysis, DongYoung, Korea, 1998.

[9] You, K.-B., Kim, B.-Y., Bae, M.-J., A study on the clarity and cognition of songs by soprano singers Focused on the relationship with the formant frequencies, International Journal of Engineering Research and Technology, 2020, 13(1), pp. 88-93 
International Journal of Engineering Research and Technology. ISSN 0974-3154, Volume 13, Number 6 (2020), pp. 1379-1385 (C) International Research Publication House. https://dx.doi.org/10.37624/IJERT/13.6.2020.1379-1385

[10] Ahn, I.-S., Kim, B.-Y., You, K.-B., Bae, M.-J., A Study on the Characteristics of an EEG Based on a Singing Bowl's Sound Frequency, Studies in Computational Intelligence 789, 2019, pp. 233-243

[11] Kim, B.-Y., Lee, S.-T., Bae, M.-J., A study on the validity of speaker identification using sound color marker, International Journal of Engineering Research and Technology, 2019, 12(2), pp. 157-161 